Bondar O. V. Prognostic potential of proliferative activity index in assessing the effectiveness of complex neoadjuvant treat ment of locally advanced breast cancer. Journal of Education, Health and Sport. 2019;9(12):298-308. eISSN 2391-8306. DOI http://dx.doi.org/10.12775/JEHS.2019.09.12.030

https://apcz.umk.pl/czasopisma/index.php/JEHS/article/view/JEHS.2019.09.12.030

http://dx.doi.org/10.5281/zenodo.3966346

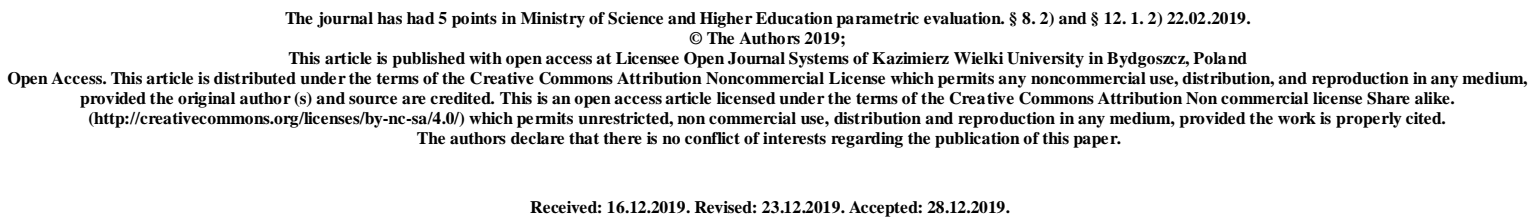

UDC 618.19-006.6-08:615.28.003.12

\title{
PROGNOSTIC POTENTIAL OF PROLIFERATIVE ACTIVITY INDEX IN ASSESSING THE EFFECTIVENESS OF COMPLEX NEOADJUVANT TREATMENT OF LOCALLY ADVANCED BREAST CANCER
}

\author{
O. V. Bondar
}

\section{Odessa National Medical University, Odessa, Ukraine}

\section{Abstract}

In recent years, breast cancer (breast cancer) has been the most common cancer and the most common cause of disability among women in developed countries. The aim of the study - determination of the role of Ki-67 and PCNA nuclear markers for the evaluation and prediction of the effectiveness of neoadjuvant antitumor treatment with the use of polychemotherapy in systemic (SPHT), endolymphatic (ELPHT) and selective intra-arterial (SIAPHT) variants in patients with breast cancer.

The study was conducted on the basis of materials from 90 histories of in patients with LABC luminal type $B \mathrm{~T}_{4 \mathrm{~A}-\mathrm{D}} \mathrm{N}_{0-2} \mathrm{M}_{0}$. The total sample was divided into three subgroups by parameter of route of neoadjuvant polychemotherapy (PCT): first control group, 22 patients systemic PCT; the second control group (27 patients) - endolymphatic PCT; study group (41 patients) - selective intra-arterial PCT.

Clinical effect with qualitative changes of local status and transfer of patients to the category of those with resectable tumors appeared in $46 \%$ of women of the first control group 
after 6 courses of SPCT, in 59\% of the second control group after 4 courses of ELPCT and in $90 \%$ of the studied group after 3 courses SIAPCT.

After systemic and endolymphatic PCT, reductions in Ki-67 and PCNA levels were determined to be insignificant $(\mathrm{p}>0.05)$ by the Mac-Nemar criterion $\chi^{2}$. For selective intraarterial techniques, the dynamics were considered significant $(\mathrm{p}<0.05)$. Intergroup comparisons revealed a statistical advantage in favor of the third group for Pearson's $\chi^{2}$ compared to the first and second ones. In the study of the association between the fact of radical surgery and the initial marker levels, a strong prognostic property of Ki-67 and PCNA was determined up to $25 \%$ with respect to the outcome of future comprehensive treatment.

With the use of SIAPCT in the non-adjuvant treatment of breast cancer by Ki-67 and PCNA in the range of up to $25 \%$, the tumor responds significantly better to the therapy and reaches a resectable status in a statistically significantly greater proportion in patients with LABC.

Keywords: locally advanced breast cancer; systemic polychemotherapy; endolymphatic polychemotherapy; selective intra-arterial polychemotherapy; proliferative activity index; Ki-67; PCNA.

Introduction. Breast cancer (BC) is the most common cancer among women worldwide [1]. This is partly due to the increase in the number of breast cancer patients [2]. Statistics show that every year more than one million women worldwide find out about their diagnosis for the first time and more than half a million die from the disease [3]. On the other hand, individualized and specialized programs for complex treatment of breast cancer have led to an increase in the survival rate of these patients [4].

The strategy of priority increase of efficiency in perspective directions create prerequisites for the development and realization of optimal tactics of medical process of BC. For initially inoperable locally spread tumors a topical issue is the development of chemotherapeutic methods of neoadjuvant preparation. The methods of physical concentration of the intensity of cytotoxic effects is an accessible and effective research area. The ultimate goal of polychemotherapy in locally advanced breast cancer (LABC), the methods of predicting and evaluating the effectiveness of treatment is the subject of discussion in the work of leading specialists $[5,6]$.

In the context of the study of breast cancer at the stage of treatment planning, it is important to consider the key problem of the potential effectiveness of the proposed method and to predict the sensitivity of the tumor to neoadjuvant treatment in order to choose the 
appropriate route of administration of chemotherapeutic drugs. A convenient and reliable way of calculating the future result is the index of tumor cells' proliferative activity as an indirect characteristic of the degree of sensitivity to artificial damage. A promising solution to this issue is the use of immunohistochemical indicators that correlate with the cytomorphological characteristics of cell proliferation, such as Ki-67 [7, 8] and PCNA [9, 10].

The aim of the study - determination of the role of Ki-67 and PCNA nuclear markers for the evaluation and prediction of the effectiveness of neoadjuvant antitumor treatment for the use of polychemotherapy in systemic (SPCT), endolymphatic (ELPCT) and selective intra-arterial (SIAPCT) variants in patients with LABC.

\section{Materials and methods}

This study was conducted on the basis of a retrospective analysis of 90 case histories of inpatients with $\mathrm{LABC} \mathrm{T}_{4 \mathrm{~A}-\mathrm{D}} \mathrm{N}_{0-2} \mathrm{M}_{0}$ of luminal type $\mathrm{B}$ who received special complex neoadjuvant treatment at the surgical wards of the Donetsk Regional Antineoplastic Center and the Center of Reconstructive and Rehabilitation Medicine (University Clinic) of the Odessa National Medical University in the period of 2012-2016.

After standardization by target age and clinical parameters, the total sample was subdivided into three subgroups according to the route of administration of polychemotherapy (PCT), which was used as part of complex neoadjuvant treatment: the first control group (22 patients) receiving systemic PCT; the second control group (27 patients) who had endolymphatic PCT; study group (41 patients) who underwent selective intra-arterial PCT.

Proliferative activity was determined by immunohistochemical study using antibodies to Ki-67, PCNA (Thermo Fisher Scientific, USA). As a minimum number of proliferating cells, a fraction of 1000 tumor cells was selected for evaluation as the minimum number to obtain representative results. The value of IGC markers was expressed as a percentage of cells with positive staining. According to the recommendations of the 14th St. Gallen Consensus, which recommended setting a Ki-67 limit value of 15 to $30 \%$, the results of our study showed a median of $24 \%$. In the first approximation, $25 \%$ is chosen as the dichotomization point. After studying the correlation between the markers, a similar operation was performed for PCNA - with a similar threshold of $25 \%$.

The clinical course of the disease and the long-term results of treatment were evaluated according to the following parameters: total life expectancy of patients with LABC from the moment of diagnosis; overall and disease-free survival for 5 years; frequency of hematogenous metastasis. In the course of the work we used the technique of evaluating the 
effectiveness of treatment of solid tumors on the RECIST scale (Response Evaluation Criteria in Solid Tumors).

At all stages of the statistical analysis, standard features of MS Excel were used to prepare the primary spreadsheets and group the features. The mean $(\mathrm{M})$, standard error $(\mathrm{m})$, and median were calculated to evaluate the quantitative indicators. Pearson's $\chi 2$ criterion was used to compare non-parametric indicators, and Mann-Whitney test was used for parametric values. In order to estimate the incremental changes in nonparametric indices within one group, the Mc-Nemar criterion $\chi^{2}$ was used, and the Wilcoxon test was used for parametric values. In all cases, the differences were considered statistically significant at a significance level of $\mathrm{p}<0.05$.

\section{Results}

After neoadjuvant treatment, 63 patients $(10(45.5 \%)$ in the first group, $16(59.3 \%)$ in the second, $37(90.2 \%)$ in the third) achieved a resectable tumor with subsequent radical mastectomy (Maden; Fig. 1-3).

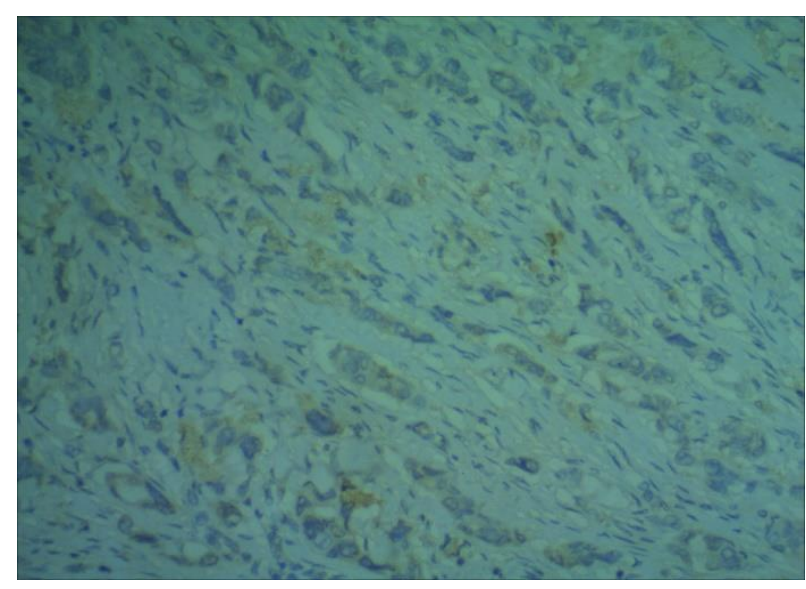

A

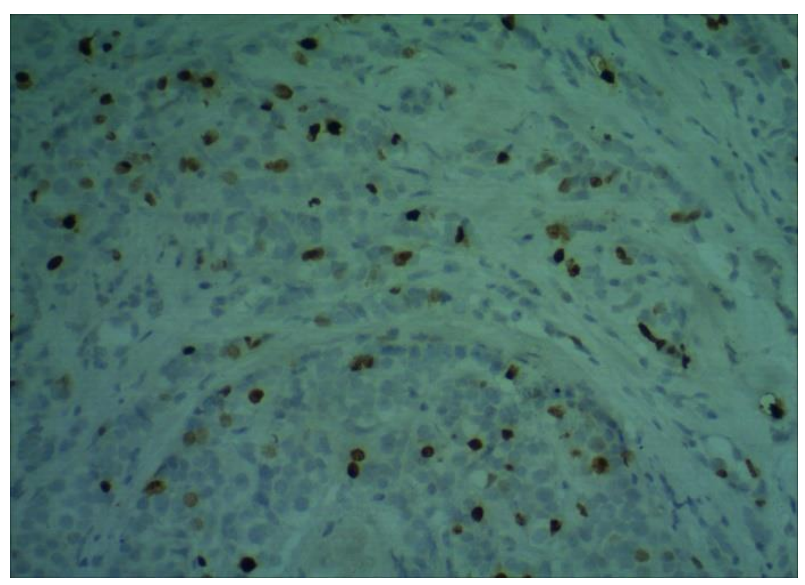

B

Fig. 1a, b. Patient A. Cr mammae sinistrae. $\mathrm{T}_{4 \mathrm{c}} \mathrm{N}_{1} \mathrm{M}_{0}$. Invasive intraductal carcinoma G2. Luminal type B. Proliferative activity index 25\% for Ki-67 (300x), (a), 24\% for PCNA (300x), (b). Hospital phase 0 day. Scheduled neoadjuvant SIAPCT.

During the postoperative study of patients' biopsy materials, additional immunohistochemical studies were performed on nuclear markers of proliferative activity: Ki-67, PCNA (Table 1). 


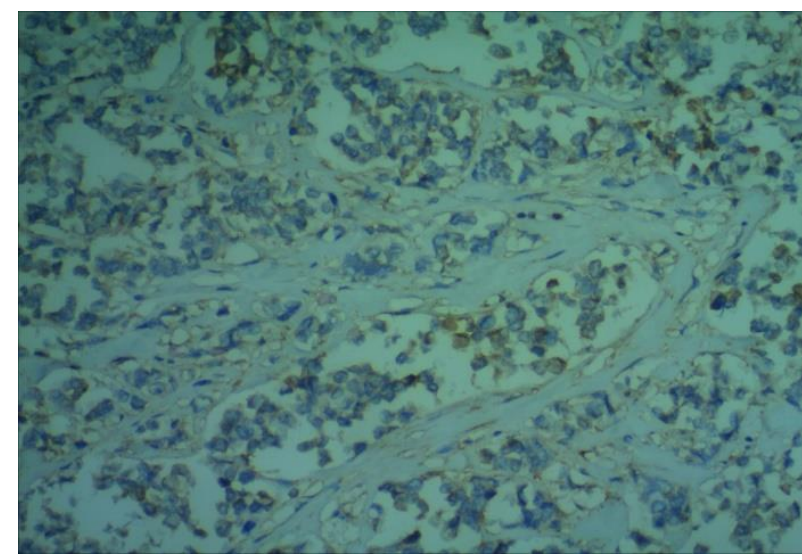

A

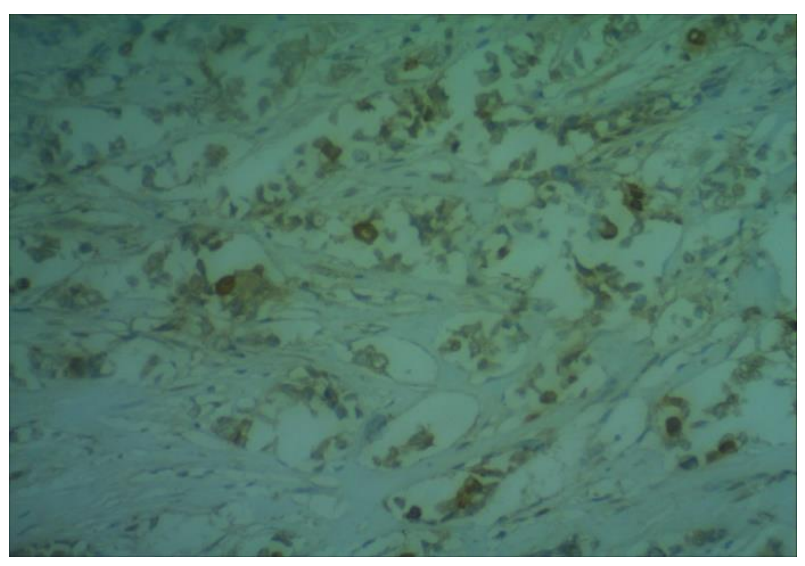

B

Fig. 2a, b. Patient B. Cr mammae dextrae. T4bN1M0. Invasive intraductal carcinoma G2. Luminal type B. Proliferative activity index 21\% for Ki-67 (300x), (a), 19\% for PCNA (300x), (b). Hospital phase 0 day. Scheduled neoadjuvant SIAPCT.

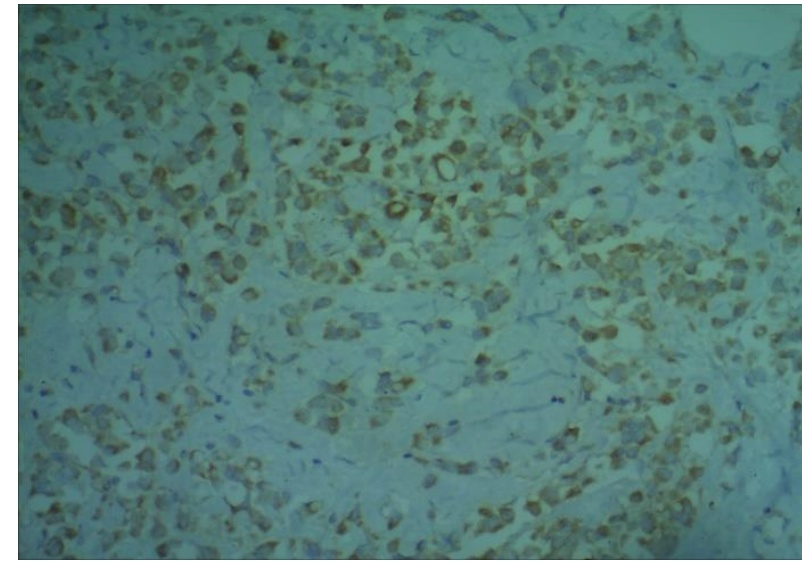

A

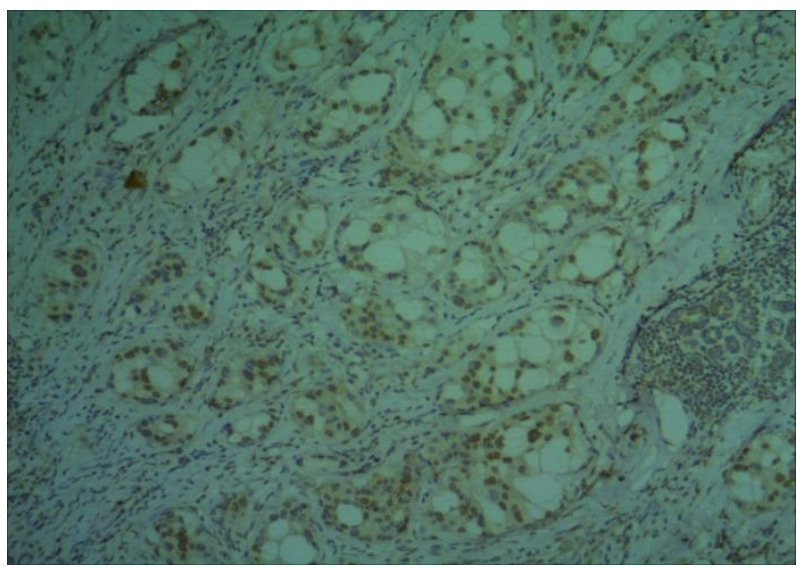

B

Fig. 3a, b. Patient B. Cr mammae dextrae. $\mathrm{T}_{4 \mathrm{~d}} \mathrm{~N}_{1} \mathrm{M}_{0}$. Invasive intraductal carcinoma G2. Luminal type B. Proliferative activity index 24\% for Ki-67 (300x), (a), 24\% for PCNA (300x), (b). Hospital phase 0 day. Scheduled neoadjuvant SIAPCT.

As a result of neo-adjuvant SPCT: the proportion of patients with low Ki-67 increased from 13 to 14 with a general decrease to $19.6 \pm 2.2$ ( $>>0.05)$. The mean value in patients with high Ki-67 levels was $31.6 \pm 6.3$ ( $p>0.05$ ). The proportion of patients with low PCNA levels increased from 11 to 12 with a general decrease to $18.2 \pm 1.6(\mathrm{p}>0.05)$. The mean of 10

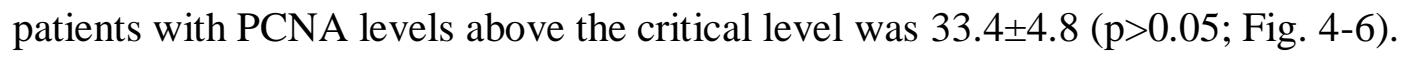


Table 1

Distribution of patients in accordance with IHC characteristics of tumor biopsy material of Ki-67 and PCNA before treatment

\begin{tabular}{|c|c|c|c|c|}
\hline \multirow{2}{*}{$\begin{array}{l}\text { IHC tumor } \\
\text { type }\end{array}$} & \multicolumn{4}{|c|}{ Number of samples / $\mathrm{M} \pm \mathrm{m}$ / Median } \\
\hline & Group 1 & Group 2 & Group 3 & Total \\
\hline $\begin{array}{c}\mathrm{Ki}-67 \\
{[<25 \%]}\end{array}$ & $\begin{array}{c}13(59 \%) / \\
20.4 \pm 3.7 / \\
25\end{array}$ & $\begin{array}{c}16(59 \%) / \\
19.3 \pm 3.1 / \\
23 \\
\end{array}$ & $\begin{array}{c}26(63 \%) / \\
19.8 \pm 2.4 / \\
22 \\
\end{array}$ & $\begin{array}{c}55(61.1 \%) \\
20.0 \pm 2.9 \\
21 \\
\end{array}$ \\
\hline $\begin{array}{c}\mathrm{Ki}-67 \\
{[>25 \%]}\end{array}$ & $\begin{array}{c}9(41 \%) / \\
34.0 \pm 6.8 / \\
32.5 \\
\end{array}$ & $\begin{array}{c}11(41 \%) / \\
35.5 \pm 6.9 / \\
35\end{array}$ & $\begin{array}{c}15(37 \%) / \\
34.4 \pm 5.8 / \\
33\end{array}$ & $\begin{array}{c}35(38.9 \%) \\
34.6 \pm 6.4 \\
31.5\end{array}$ \\
\hline $\begin{array}{l}\text { Total } \\
\text { Ki-67 }\end{array}$ & $\begin{array}{c}22(100 \%) / \\
27.8 \pm 5.9 / \\
25\end{array}$ & $\begin{array}{c}27(100 \%) / \\
26.3 \pm 7.5 / \\
24\end{array}$ & $\begin{array}{c}41(100 \%) / \\
26.8 \pm 7.5 / \\
22\end{array}$ & $\begin{array}{c}90(100 \%) \\
26.4 \pm 7.1 \\
24 \%\end{array}$ \\
\hline $\begin{array}{l}\text { PCNA } \\
{[<25 \%]}\end{array}$ & $\begin{array}{c}11(50 \%) / \\
20.6 \pm 1.5 / \\
21\end{array}$ & $\begin{array}{c}14(52 \%) / \\
21.7 \pm 2.0 / \\
21\end{array}$ & $\begin{array}{c}22(54 \%) / \\
19.4 \pm 2.0 / \\
19\end{array}$ & $\begin{array}{c}47(52.2 \%) \\
20.3 \pm 2.1 \\
20 \% \\
\end{array}$ \\
\hline $\begin{array}{l}\text { PCNA } \\
{[>25 \%]}\end{array}$ & $\begin{array}{c}11(50 \%) / \\
39.3 \pm 5.8 / \\
40\end{array}$ & $\begin{array}{c}13(48 \%) / \\
37.4 \pm 5.2 / \\
37.5\end{array}$ & $\begin{array}{c}19(46 \%) / \\
37.5 \pm 5.7 / \\
37\end{array}$ & $\begin{array}{c}43(47.8 \%) \\
38.2 \pm 5.9 \\
37.5 \% \\
\end{array}$ \\
\hline $\begin{array}{l}\text { Total } \\
\text { PCNA }\end{array}$ & $\begin{array}{c}22(100 \%) / \\
29.0 \pm 8.6 / \\
30 \\
\end{array}$ & $\begin{array}{c}27(\mathbf{1 0 0 \%} \% / \\
29.0 \pm 8.6 / \\
27 \\
\end{array}$ & $\begin{array}{c}41(100 \%) / \\
27.8 \pm 9.0 / \\
24\end{array}$ & $\begin{array}{c}90(100 \%) \\
29.0 \pm 8.6 \\
26.5 \%\end{array}$ \\
\hline
\end{tabular}

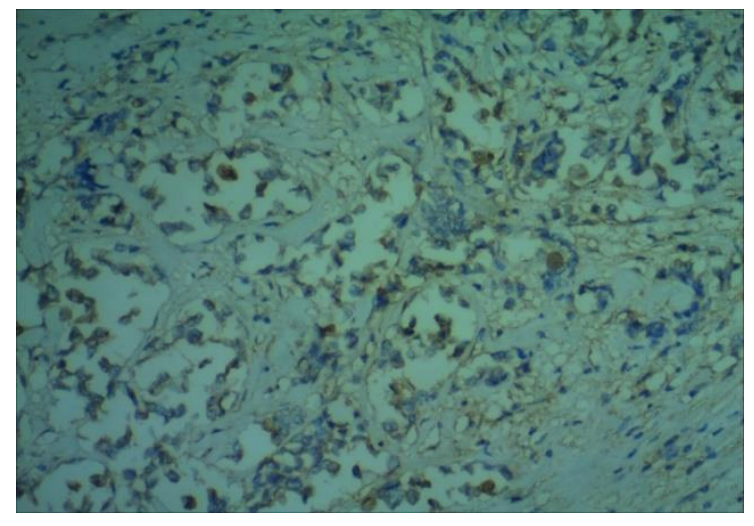

A

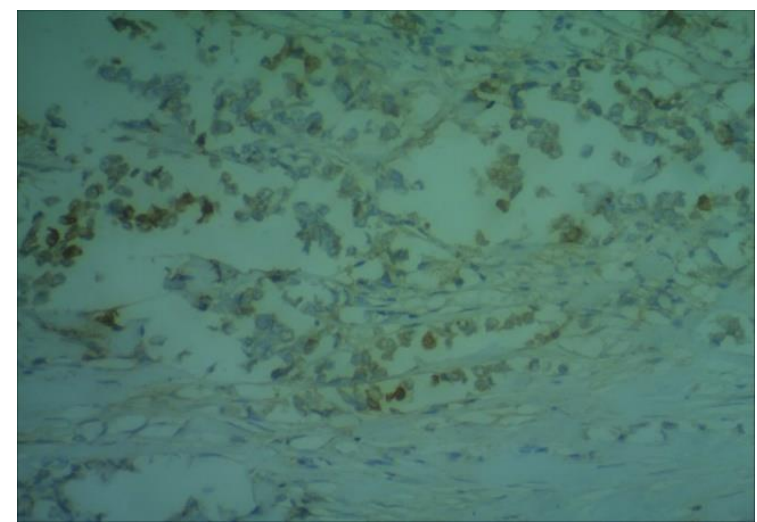

B

Fig. 4a, b. Patient A. Cr mammae sinistrae. $\mathrm{T}_{4 \mathrm{c}} \mathrm{N}_{2} \mathrm{M}_{0}$. Invasive intraductal carcinoma G3. Luminal type B. Proliferative activity index of 15\% Ki-67 (300x), (a), 12\% PCNA (300x), (b). Hospital phase 90 day. Condition after 3 courses of SIAPCT (CAMF). Therapeutic pathomorphosis, stage III. 


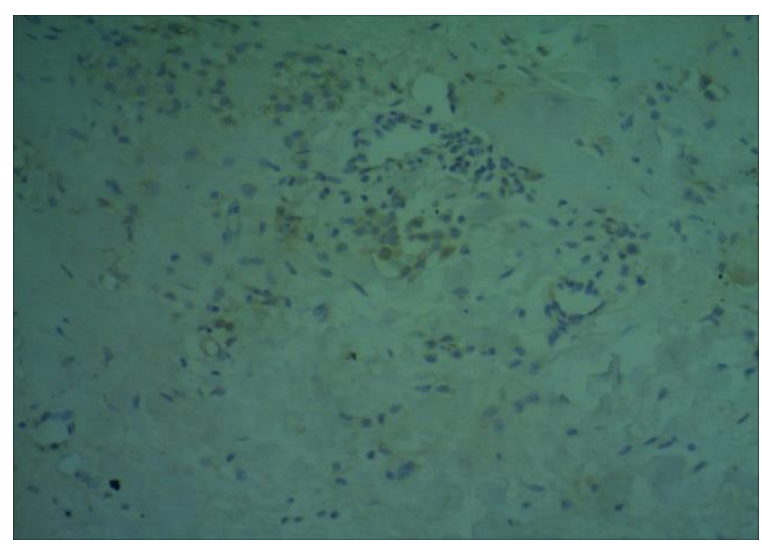

A

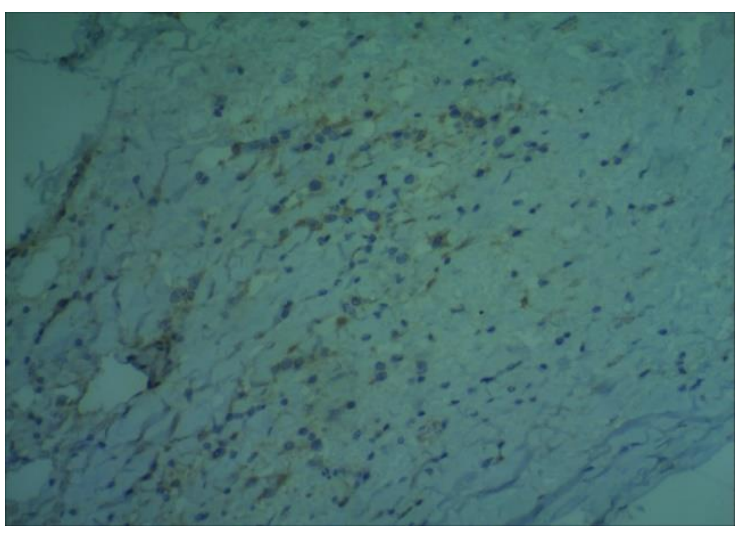

B

Fig. 5a, b. Patient B. Cr mammae dextrae. $\mathrm{T}_{4 \mathrm{~b}} \mathrm{~N}_{1} \mathrm{M}_{0}$. Invasive intraductal carcinoma G3. Luminal type B. Proliferative activity index of 15\% Ki-67 (300x), (a), 15\% PCNA (300x), (b). Hospital phase 90 day. Condition after 3 courses of SIAPCT (CAMF). Therapeutic pathomorphosis, stage III.

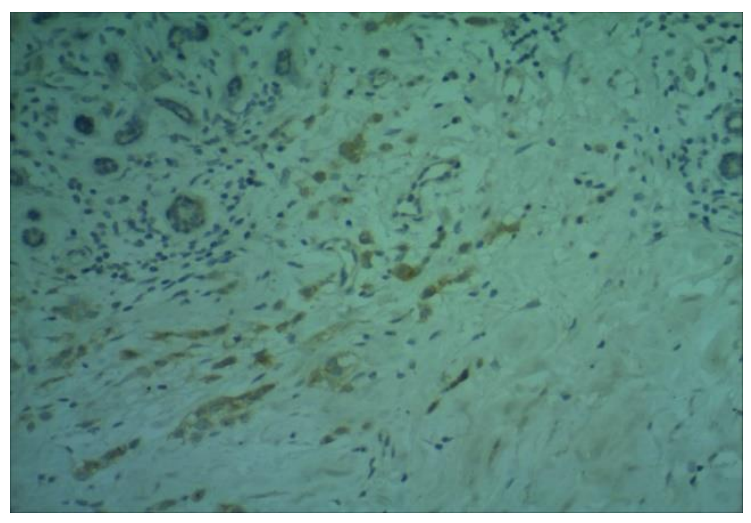

A

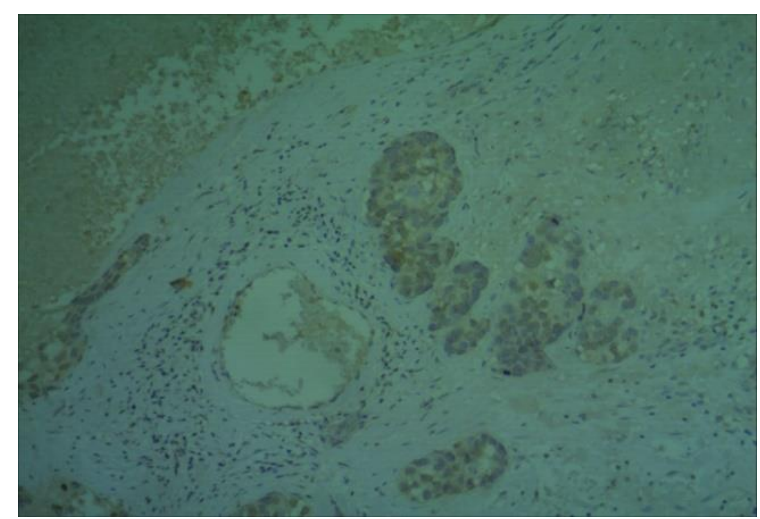

B

Fig. 6a, b. Patient B. Cr mammae dextrae. $\mathrm{T}_{4 \mathrm{~d}} \mathrm{~N}_{0} \mathrm{M}_{0}$. Invasive intraductal carcinoma G3. Luminal type B. Proliferative activity index of 12\% Ki-67 (300x), (a), 12\% PCNA (300x), (b). Hospital phase 90 day. Condition after 3 courses of SIAPCT (CAMF). Therapeutic pathomorphosis, stage III.

After conducting the planned course of neoadjuvant ELPCT, the number of patients in this group with high $\mathrm{Ki}-67$ decreased from 11 to 9 with $1.4 \pm 4.3$ ( $>>0.05$; Table 2). The average value of the proliferation marker under study was $18.2 \pm 2.2(\mathrm{p}>0.05)$ in 18 individuals with a Ki-67 subthreshold level. The number of patients in this group with high PCNA levels decreased from 13 to 12 with an average of 32.0 \pm 3.2 ( $\mathrm{p}>0.05)$. The mean of the proliferation marker under study was $18.5 \pm 2.0(\mathrm{p}>0.05)$ in 15 individuals with a low PCNA subgroup. 
Table 2

Distribution of patients according to IHC characteristics of tumor biopsy material for Ki-67 and PCNA after treatment

\begin{tabular}{|c|c|c|c|c|}
\hline \multirow{2}{*}{$\begin{array}{l}\text { IHC tumor } \\
\text { type }\end{array}$} & \multicolumn{4}{|c|}{ Number of samples / M $\pm \mathrm{m} /$ Median } \\
\hline & Group 1 & 2 група & Group 1 & Всього \\
\hline $\begin{array}{c}\mathrm{Ki}-67 \\
{[<25 \%]}\end{array}$ & $\begin{array}{c}14(64 \%) / \\
19.6 \pm 2.2 / \\
20\end{array}$ & $\begin{array}{c}18(67 \%) / \\
18.2 \pm 2.2 / \\
17.5\end{array}$ & $\begin{array}{c}31(76 \%) / \\
8.3 \pm 1.3 / \\
8\end{array}$ & $\begin{array}{c}63(70 \%) \\
13.7 \pm 5.2 \\
14.5\end{array}$ \\
\hline $\begin{array}{c}\mathrm{Ki}-67 \\
{[>25 \%]}\end{array}$ & $\begin{array}{c}8(36 \%) / \\
31.6 \pm 6.3 / \\
28 \\
\end{array}$ & $\begin{array}{c}9(33 \%) / \\
31.4 \pm 4.3 / \\
30\end{array}$ & $\begin{array}{c}10(24 \%) / \\
32.5 \pm 4.5 / \\
35\end{array}$ & $\begin{array}{c}27(30 \%) \\
31.9 \pm 4.9 \\
30\end{array}$ \\
\hline $\begin{array}{l}\text { Total } \\
\text { Ki-67 }\end{array}$ & $\begin{array}{c}22(100 \%) / \\
23.8 \pm 5.7 / \\
21.5 \\
\end{array}$ & $\begin{array}{c}27(100 \%) / \\
22.1 \pm 6.7 / \\
19\end{array}$ & $\begin{array}{c}41(100 \%) / \\
15.9 \pm 8.9 / \\
11\end{array}$ & $\begin{array}{c}90(100 \%) \\
19.7 \pm 8.2 \\
18 \\
\end{array}$ \\
\hline $\begin{array}{l}\text { PCNA } \\
{[<25 \%]}\end{array}$ & $\begin{array}{c}12(55 \%) / \\
18.2 \pm 1.6 / \\
19.5\end{array}$ & $\begin{array}{c}15(56 \%) / \\
18.5 \pm 2.0 / \\
19\end{array}$ & $\begin{array}{c}30(72 \%) / \\
8.6 \pm 1.2 / \\
9\end{array}$ & $\begin{array}{c}57(63 \%) \\
13.8 \pm 5.4 \\
11\end{array}$ \\
\hline $\begin{array}{l}\text { PCNA } \\
{[>25 \%]}\end{array}$ & $\begin{array}{c}10(45 \%) / \\
33.4 \pm 4.8 / \\
34\end{array}$ & $\begin{array}{c}12(44 \%) / \\
32.0 \pm 3.2 / \\
30.5\end{array}$ & $\begin{array}{c}11(27 \%) / \\
28.6 \pm 1.9 / \\
29\end{array}$ & $\begin{array}{c}33(37 \%) \\
31.3 \pm 3.6 \\
30\end{array}$ \\
\hline $\begin{array}{l}\text { Total } \\
\text { PCNA }\end{array}$ & $\begin{array}{c}22(100 \%) / \\
26.0 \pm 6.8 / \\
24.5\end{array}$ & $\begin{array}{c}27(100 \%) / \\
23.9 \pm 7.4 / \\
25\end{array}$ & $\begin{array}{c}41(100 \%) / \\
14.0 \pm 7.8 / \\
9\end{array}$ & $\begin{array}{c}90(100 \%) \\
19.9 \pm 8.9 \\
18\end{array}$ \\
\hline
\end{tabular}

Due to neoadjuvant SIAPCT, the total number of patients with low Ki-67 increased by 5 with a decrease in the Ki-67 proliferative activity index to $8.3 \pm 1.3$ ( $\mathrm{p}<0.05$ ). The mean control level in patients with high levels was 32.5 \pm 4.5 ( $p>0.05)$. The number of patients with subthreshold PCNA increased by 8 with a decrease in PCNA proliferative activity index to $8.6 \pm 1.2(\mathrm{p}<0.05)$. The mean marker level in 11 high-grade women was $28.6 \pm 1.9(\mathrm{p}>0.05)$.

The data obtained show a strong correlation between the two nuclear markers of tumor proliferative activity (PA) in the dynamics due to neoadjuvant polychemotherapy treatment as a result of effective reduction of the activity of growth and division of atypical cells and form an integrative index. By reducing this indicator, the effectiveness of all techniques was higher in patients with low values of IHC markers with a single redistribution $(p>0.05)$ of the number of patients in the first and second groups and significant $(\mathrm{p}<0.05)$ in the third.

After systemic and endolymphatic PCT, reductions in Ki-67 and PCNA levels were determined to be insignificant $(p>0.05)$ by the McManard criterion $\chi 2$. For selective intra- 
arterial techniques, the dynamics were considered significant ( $\mathrm{p}<0.05)$. Intergroup comparisons revealed a statistical advantage in favor of the third group for Pearson's $\chi^{2}$ compared to the first and second.

In the study of the association between the fact of radical surgery and the initial marker levels, a strong prognostic property of Ki-67 and PCNA was determined up to $25 \%$ with respect to the outcome of future comprehensive treatment.

A correlation was established between the low level of Ki-67 marker before treatment and PCNA after non-adjuvant polychemotherapy in all three groups with operative treatment. The incomplete correlation between them testifies to their potentiating nature as a part of the integrative index of the proliferative activity index and the urgency of complex use.

Quantitative and qualitative clinical and immunohistochemical changes in patients of the third group confirm higher efficiency of SIAPCT in comparison with SPCT and ELPCT in the non-adjuvant treatment of LABC.

For patients of the first control group with luminal type In breast cancer, the average life expectancy since diagnosis was $2.61 \pm 0.9$ years, overall three-year survival was $54.5 \%$ (12 patients); for the second control group, average life expectancy was $2.9 \pm 0.5$ years, overall three-year survival was 55.6\% (15 patients); of the study group - average life expectancy of $3.8 \pm 0.7$ years, overall three-year survival rate $-73.2 \%$ (30 patients).

In the detailed analysis in the low-baseline Ki-67 and PCNA subgroup, the average life expectancy from diagnosis in the first group was $3.43 \pm 0.4$ years, three-year survival was $54.5 \%$ (12 patients); in the second group the average life expectancy was $3.32 \pm 0.2$ years, the three-year survival rate was $55.6 \%$ (15 patients); in the third, the average life expectancy was $4.24 \pm 0.4$ years, the three-year survival rate was $63.4 \%$ (26 patients).

Instead, in the high-baseline Ki-67 and PCNA subgroup, the mean life expectancy from diagnosis in the first group was $1.67 \pm 0.2$ years, three-year survival was $0 \%$; in the second group the average life expectancy was $2.38 \pm 0.2$ years, the three-year survival rate was $0 \%$; in the third group the average life expectancy was $2.61 \pm 0.3$ years, the three-year survival rate was $0 \%$.

These data demonstrate a mediated strong association of low proliferative $\mathrm{BC}$ activity on Ki-67 and PCNA with better long-term survival rates due to the achievement of resectable tumor status in these patients and surgery.

During the postoperative study of the biopsy materials of these patients, immunohistochemical study of the permanent preparations for the presence and determination of reference levels of nuclear markers of proliferative activity (Ki-67, PCNA) and MSI was 
performed. In accordance with the recommendations of the 14th St. Gallen Consensus, following threshold levels were set: Ki-67 - 25\% PCNA - 25\%.

After systemic and endolymphatic PCT, reductions in Ki-67 and PCNA levels were determined to be insignificant $(\mathrm{p}>0.05)$ by the McManard $\chi^{2}$ criterion. For selective intraarterial techniques, the dynamics were considered significant $(\mathrm{p}<0.05)$. Intergroup comparisons revealed a statistical advantage in favor of the third group for Pearson's $\chi^{2}$ compared to the first and second.

In the study of the association between the fact of radical surgery and the initial marker levels, a strong prognostic property of Ki-67 and PCNA was determined up to $25 \%$ with respect to the outcome of future comprehensive treatment.

A correlation was established between the low level of Ki-67 marker before treatment and PCNA after non-adjuvant polychemotherapy in all three groups with operative treatment. The incomplete correlation between them testifies to their potentiating nature as a part of the integrative index of the proliferative activity index and the urgency of complex use.

\section{Conclusions}

1. The technique of selective intra-arterial polychemotherapy in combination with radiation therapy at the neoadjuvant stage of treatment of luminal type B MR has allowed to achieve a resectable tumor condition in $90 \%$ of cases (for systemic PCT, this result was set at $46 \%$, for endolymphatic $-59 \%$.

2. The use of tumor proliferative activity index based on the markers Ki-67 (utility model patent No. 136691 dated 08/27/2019) and PCNA (utility model patent No. 136692 dated 08/27/2019) was determined as an effective method of descriptive and predictive evaluation of the effectiveness of complex antitumor treatment with setting a threshold value for both IHC at $25 \%$, within which the tumor responds significantly to neoadjuvant combination treatment $(\mathrm{p}<0.05)$ and reaches a resectable status in a statistically significantly greater proportion of patients with LABC.

\section{REFERENCES}

1. Mahvi D.A., Liu R., Grinstaff M.W., Colson Y.L., Raut C.P. Local Cancer Recurrence: The Realities, Challenges, and Opportunities for New Therapies. CA Cancer J. Clin. 2018; 68 (6): 488-505.

2. Narod S.A. Personalised medicine and population health: breast and ovarian cancer. Hum. Genet. 2018; 137 (10): 769-778. 
3. PDQ Screening and Prevention Editorial Board. PDQ Cancer Information Summaries [Internet]. National Cancer Institute (US); Bethesda (MD): Dec 18, 2019. Breast Cancer Screening (PDQ®): Health Professional Version.

4. Parada H., Sun X., Tse C.K., Olshan A.F., Troester M.A.. Lifestyle Patterns and Survival Following Breast Cancer in the Carolina Breast Cancer Study. Epidemiology. 2019; 30 (1): 83-92.

5. Stamatovic L., Susnjar S., Gavrilovic D., Minic I., Ursulovic T., Dzodic R. The influence of breast cancer subtypes on the response to anthracycline neoadjuvant chemotherapy in locally advanced breast cancer patients. J BUON. 2018; 23 (5): 1273-1280.

6. Saw S., Lim J., Lim S.H., Wong M., Lim C., Yap Y.S. Patterns of relapse after neoadjuvant chemotherapy in breast cancer: implications for surveillance in clinical practice. Breast Cancer Res Treat. 2019; 177 (1): 197-206.

7. Niazi M.K.K., Senaras C., Pennell M.,Arole V., Tozbikian G., Gurcan M.N. Relationship between the Ki67 index and its area based approximation in breast cancer. BMC Cancer. 2018; 18 (1): 867.

8. Guo J.L., Gu S.Q., Li Y., Zhang X.Y. Evaluation of clinical significance of endoglin expression during breast cancer and its correlation with ER and PCNA. Eur. Rev. Med. Pharmacol. Sci. 2017; 21 (23): 5402-5407.

9. Juríková M., Danihel L, Polák Š., Varga I. Ki67, PCNA, and MCM proteins: Markers of proliferation in the diagnosis of breast cancer. Acta Histochem. 2016; 118 (5): 544-552.

10. Sánchez-Muñoz A., Plata-Fernández Y.M., Fernández M., Jaén-Morago A., Fernández-Navarro M., de la Torre-Cabrera C., Ramirez-Tortosa C., Lomas-Garrido M., Llácer C., Navarro-Perez V., Alba-Conejo E., Sánchez-Rovira P. The role of immunohistochemistry in breast cancer patients treated with neoadjuvant chemotherapy: an old tool with an enduring prognostic value. Clin. Breast Cancer. 2013; 13 (2): 146-152. 